\title{
Characterizations of novel pesticide-degrading bacterial strains from industrial wastes found in the industrial cities of Pakistan and their biodegradation potential
}

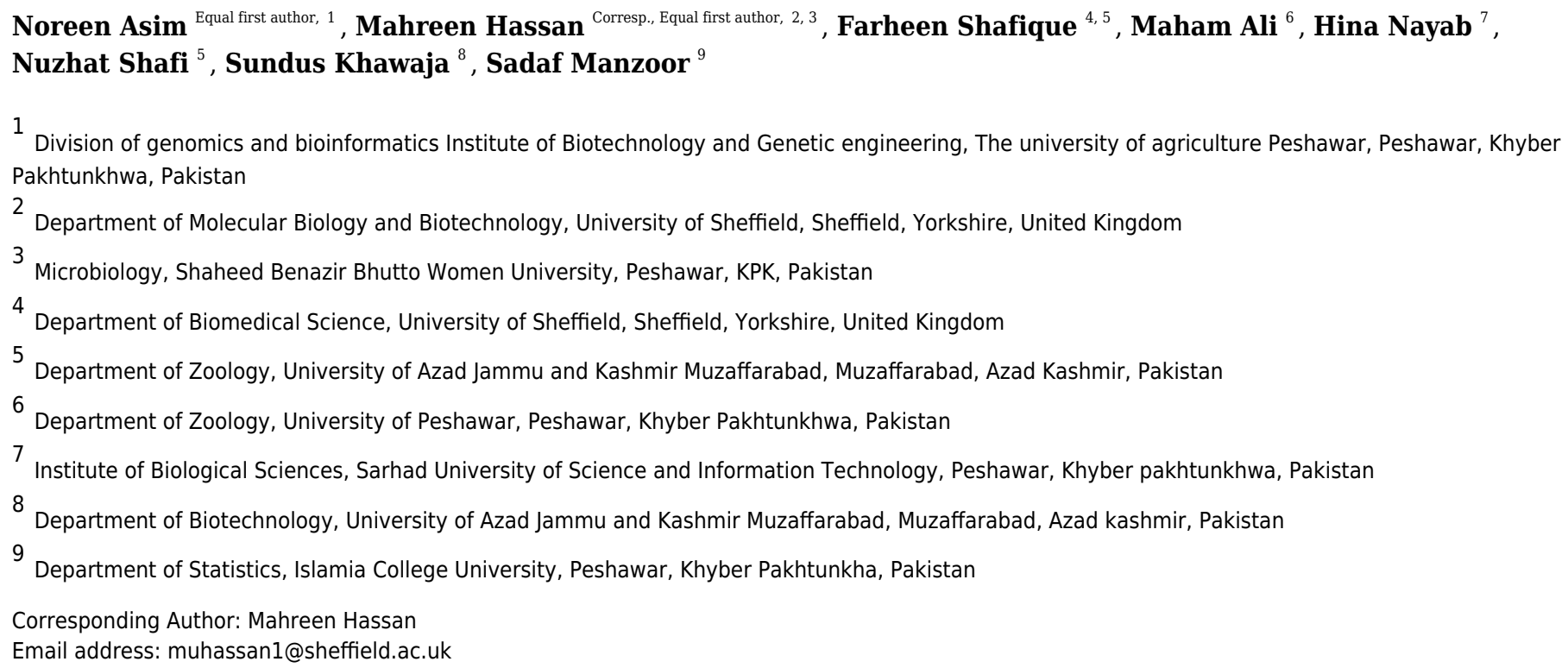

Background Lack of infrastructure for disposal of effluents in industries leads to severe pollution of natural resources in developing countries. These pollutants accompanied by solid waste are equally hazardous to biological growth. Natural attenuation of these pollutants was evidenced that involved degradation by native microbial communities. The current study encompasses the isolation of pesticide-degrading bacteria from the vicinity of pesticide manufacturing industries. Methods The isolation and identification of biodegrading microbes was done. An enrichment culture technique was used to isolate the selected pesticide-degrading bacteria from industrial waste. Results Around 20 different strains were isolated, among which 6 isolates showed significant pesticide biodegrading activity. After 16S rRNA analysis, two isolated bacteria were identified as Acinetobacter baumannii (5B) and Acidothiobacillus ferroxidans, and the remaining four were identified as different strains of Pseudomonas aeruginosa (1A, 2B, 3C, 4D). Phylogenetic analysis confirmed their evolution from a common ancestor. All strains showed distinctive degradation ability up to 36 hours. The Pseudomonas aeruginosa strains 1A and 4D showed highest degradation percentage of about $80 \%$ for DDT, and $P$. aeruginosa strain $3 C$ showed highest degradation percentage, i.e., 78\% for aldrin whilst in the case of malathion, $A$. baumannii and $A$. ferroxidans have shown considerable degradation percentages of $53 \%$ and $54 \%$, respectively. Overall, the degradation trend showed that all 
the selected strains can utilize the given pesticides as sole carbon energy sources even at a concentration of $50 \mathrm{mg} / \mathrm{mL}$. Conclusion This study provided strong evidence for utilizing these strains to remove persistent residual pesticide; thus, it gives potential for soil treatment and restoration. 
1 Characterizations of novel pesticide-degrading bacterial

2 strains from industrial wastes found in the industrial cities of

3 Pakistan and their biodegradation potential

4

5 Noreen Asim/Noreen Azhar ${ }^{1}$, Mahreen UI Hassan²,3, Farheen Shafique ${ }^{4}$, Maham Ali5,

6 Hina Nayab ${ }^{6}$, Nuzhat Shafi ${ }^{7}$, Sundus Khawaja ${ }^{8}$, Sadaf Manzoor ${ }^{9}$

7 1Division of Genomics and Bioinformatics, Institute of Biotechnology and Genetic

8 Engineering, The University of Agriculture, Peshawar, Pakistan

9 2Department of Microbiology, Shaheed Benazir Bhutto Women University, Peshawar ,

\section{Pakistan}

3Department of Molecular Biology and Biotechnology, University of Sheffield, Sheffield, UK

${ }^{4}$ Department of Biomedical Science, University of Sheffield, Sheffield, UK

${ }^{5}$ Department of Zoology, University of Peshawar, Peshawar , Pakistan

${ }^{6}$ Institute of Biological Sciences, Sarhad University of Science and Information Technology, Peshawar, Pakistan

${ }^{7}$ Department of Zoology, University of Azad Jammu and Kashmir, Muzaffarabad , Pakistan

¿University of Azad Jammu and Kashmir, Department of Biotechnology, Muzaffarabad, Pakistan

${ }^{9}$ Department of Statistics, Islamia college University, Peshawar, Khyber Pakhtunkhwa, Pakistan

Corresponding author: $\quad$ *Mahreen ul Hassan

PhD Scholar

Dept of Molecular Biology and Biotechnology

University of Sheffield

Firth Court,

Western Bank

Sheffield 


\section{Abstract}

Background Lack of infrastructure for disposal of effluents in industries leads to severe pollution of natural resources in developing countries. These pollutants accompanied by solid waste are equally hazardous to biological growth. Natural attenuation of these pollutants was evidenced that involved degradation by native microbial communities. The current study encompasses the isolation of pesticide-degrading bacteria from the vicinity of pesticide manufacturing industries. Methods The isolation and identification of biodegrading microbes was done. The pesticide-degrading bacteria were isolated by using enrichment culture method from industrial waste. Results Around 20 different strains were isolated, among which 6 isolates showed significant pesticide biodegrading activity. After $16 \mathrm{~S}$ rRNA analysis, two isolated bacteria were identified as Acinetobacter baumannii (5B) and Acidothiobacillus ferroxidans, and the remaining four were identified as different strains of Pseudomonas aeruginosa (1A, 2B, 3C, 4D). Phylogenetic analysis confirmed their evolution from a common ancestor. All strains showed distinctive degradation ability up to 36 hours. The Pseudomonas aeruginosa strains $1 \mathrm{~A}$ and 4D showed highest degradation percentage of about $80 \%$ for DDT, and $P$. aeruginosa strain $3 \mathrm{C}$ showed highest degradation percentage, i.e., $78 \%$ for aldrin whilst in the case of malathion, $A$. baumannii and $A$. ferroxidans have shown considerable degradation percentages of $53 \%$ and $54 \%$, respectively. Overall, the degradation trend showed that all the selected strains can utilize the given pesticides as sole carbon energy sources even at a concentration of $50 \mathrm{mg} / \mathrm{mL}$.

Conclusion This study provided strong evidence for utilizing these strains to remove persistent residual pesticide; thus, it gives potential for soil treatment and restoration.

Keywords organo-pesticides, biodegradation, Acinetobacter baumannii, Acidothiobacillus ferroxidans, Pseudomonas aeruginosa, 16S rRNA, malathion, DDT , aldrin 


\section{INTRODUCTION}

62 Pesticides are hydrocarbons widely used in agriculture and households to control variety 63 of pests (Bhatt et al., 2021). Pesticides were introduced in Pakistan during the 1960s in 64 the period of green revolution, and during the 1980s its applied quantity rose from 665 65 tons to 46,000 tons in the year 2000 (Syed et al., 2014). Pesticides are categorized into 66 four types: organochlorines, organophosphorus, carbamates and pyrethroids. Among 67 these, organochlorine pesticides were the primary class with high toxicity, hydrophobicity, and persistent nature. Many organochlorine pesticides have been banned. However, pesticides like chlorinated hydrocarbons such as DDT, aldrin, and dieldrin are still ignorantly used, and a significant number of obsolete pesticides have been stockpiled in developing countries (Arrebola et al., 2015). Among all the synthetic pesticides, organophosphate is the more stable and less toxic class. Therefore, their wide structural variety and diverse chemical properties enable them for multiple uses. Derivatives of these organo-chemicals are also controversial because they also have persistent effects on the surroundings when applied for a more extended period (Jayaraj $R$ et. al., 2016) and even within the organism after exposure. Organochlorine and organophosphate, even at low concentration, are toxic and carcinogenic to mammals. They can affect the nervous system, immune system, respiratory system, reproductive function, and hormonal balance, and cause serious illnesses in invertebrates and vertebrates. Accumulation of these pollutants in soil or water bodies has been the reason for the loss of many marine and sea animals. Dramatic consumption would lead to the integration of these pesticides in the food chain, which ultimately accumulate in the tissue of consumers, causing deleterious effects (Kim et al., 2017). Additionally, wide ranges of water and terrestrial ecosystems have been polluted with these compounds. The eradication and safe removal of such pollutants from the environment is essential, and industries related to pesticides are the main culprits (Hattab and Ghaly, 2012). Advanced countries have treatment facilities for safe disposal of effluents, but these issues are rarely tackled in underdeveloped and developing countries, particularly in small scale industries due to their unaffordability (Mishra S, et al., 2021). Biodegradation and detoxification with the help of native microbes are promising approaches for toxic waste removal and environmental remediation. Microbial communities on exposure to new compounds 
92 generate new enzymes with the emergence of genetic mutations to survive. Hence native 93 microbes adapt to new surroundings.

94 Furthermore, it is easy to extract genes from microbes possessing degradation ability, 95 which can be expressed in other hosts by genetic engineering (Ye et al., 2018; Regueiro 96 et al., 2015; Bhatt $\mathrm{P}$ et al., 2020). Many lower income countries do not have any facility 97 to regulate, manage, and dispose of the obsolete persistent organic pollutants. Thus, 98 implementation of cost-effective waste management procedures like bioremediation, 99 phytoremediation and bioaugmentation is needed to restore the natural resources 100 (UNEP, 2018).

101 Biodegradation of pollutants through natural attenuation is the most preferable, cost 102 effective and safest solution. But the availability, effectiveness, and popularization of 103 certain microbial communities for treatment of specific pesticides are a significant issue 104 and are under consideration by examining and isolating the native strains from such 105 contaminated (effluent) areas that combat these toxicities (Cycoń M et al., 2017). 106 Biodegradation through microbes is the most effective way to make our environment 107 pesticide free. For their sustenance, microbes utilize toxic substances such as carbon, 108 nitrogen, and phosphorus, etc. (Bhatt et al., 2021). Currently microbial degradation is 109 considered as most thorough and extensive method for biodegradation. For this purpose, 110 bacteria, fungi, and algae are all used in different ways, but the bacteria are very common.

111 In the past, many scientists have worked in search of microbes that could degrade 112 pollutants to teir non-toxic states (Huang et al., 2021). Bacteria and fungi have been 113 utilized as whole-cell biocatalysts in a variety of biotechnological processes, not only for 114 manufacturing various products but for the development of biotransformation/ 115 biodegradation reactions also (Birolli et al., 2019). Many bacterial and fungal genera such

116 as Aerobacter, Acinetobacter, Agrobacterium, Aspergillus, Bacillus, Clostridium,

117 Desulfuromonas, Enterobacter, Flavobacterium, Fusarium, Klebsiella, Lactobacillus,

118 Pasteurella, Pseudomonas, Pleurotus, Phlebia sp., Penicillium, Rhizopus,

119 Sedimentibacter, Streptococcus, and Staphylococcus were identified in degradation of

120 popular pesticides. Although many biodegrading microbes have been extensively studied

121 for their pesticide degrading ability, many scientists are still searching for better microbes 122 with high and specific efficacy (Kumar et al., 2018 and Bhatt $P$ et al., 2021). There are 
123 many bacteria which can degrade a variety of xenobiotic compounds quite efficiently

124 under controlled laboratory conditions, but they failed to do so in a natural environment

125 (Arora et al., 2018).

126 Although the use of most organo-pesticides is also banned in Pakistan, their residues still

127 exist and have accumulated in biotic and abiotic resources (Mazzon et al., 2020).

128 The current study aims to isolate and identify novel bacterial strains from the vicinity of

129 pesticide manufacturing industrial sites that could use pesticides like DDT, aldrin and

130 malathion as their nutritional source.

131 Contribution

132 Our study's uniqueness was to collect samples specifically from the unexplored points of 133 pesticide wastes to isolate the possible native bacterial strains. We also observed the 134 extent of bacterial chemical utilization capacity, especially for DDT, aldrin and malathion.

135 The study gives an insight into the soil that was chemically polluted with these pesticides

136 and could be restored for further cultivation purposes. After confirming their presence,

137 further chemical tests and morphological studies were conducted to improve our

138 understanding of these bacterial strains that can further be utilized to treat chemically

139 polluted land and water.

140

\section{Materials \& Methods}

\section{Sampling and management}

143 Samples were obtained from effluents of five industrial sites, mainly located at Faisalabad 144 and Lahore in Pakistan. Water and soil samples were randomly collected from industrial 145 drainage sources and garbage/disposal points, respectively, where the possibility of the 146 presence of effluents was higher. The soil and water samples were collected with the 147 consent of the landowner. No animal or plant species were harmed during the collection 148 process. Standard procedures were used to obtain sludge samples (Ghanem et al., 149 2007), from wastewater near industrial area carrying effluents from the pesticide 150 manufacturing plants (Farhan et al., 2012). All the reagents and chemicals were analytical 151 grade purchased from Merck, Germany, and Sigma-Aldrich USA. The pesticides 152 (malathion, DDT and aldrin) with $>99 \%$ purity were obtained from Sigma-Aldrich, USA. 153 Synthetic oligonucleotides were provided by the Integrated DNA Technologies (IDT), USA 
154 for this study. Physical samples of microbial isolates used in this study were permanently

155 deposited at National Institute of Biotechnology and Genetic Engineering (NIBGE)

156 Faisalabad, Pakistan

157

\section{Sample processing and enrichment}

159 To maintain the biological activity of the soil microflora, the samples were obtained from

160 contaminated areas in sterile polythene bags kept at $4^{\circ} \mathrm{C}$. On the day of collection, the

161 soil samples were further treated by mixing $10 \mathrm{~g}$ of soil sample in a $100 \mathrm{~mL}$ of autoclaved

162 water. The mixture was then kept at room temperature $\left(30^{\circ} \mathrm{C}\right)$ in an orbital shaker for 24

163 hours at $100 \mathrm{rpm}$. The enrichment culture method was acquired to isolate pesticide

164 biodegrading bacterial strains. To improve the likelihood of detecting pesticide-degrading

165 native microflora, samples were first supplemented with commercial-grade pesticides

166 (Khan et al., 2016). From each water and soil sample, $10 \mathrm{~mL}$ were inoculated into 100

$167 \mathrm{~mL}$ of fresh MSM broth in $250 \mathrm{~mL}$ Erlenmeyer flasks containing $20 \mathrm{mg} / \mathrm{mL}$ selected

168 pesticides as the sole source of carbon and phosphorus. The flasks were incubated for

169 seven days at $150 \mathrm{rpm}$ under ambient conditions. The cultures were gradually acclimated

170 to increase the three applied pesticides ranging from $20-50 \mathrm{mg} / \mathrm{mL}$ at weekly intervals. At

171 about a final concentration of $50 \mathrm{mg} / \mathrm{mL}$ of different pesticides, the pesticide tolerant

172 cultures were subjected to further degradation study. Media without inoculation was run

173 as a control. The experiments were performed in triplicate for authentication (Jiang et al.,

174 2019).

175 Isolation of biodegrading strains

176 For the isolation of pesticide degrading bacteria, the nutrient agar media plates were first

177 inoculated with $1 \mathrm{~mL}$ of each enriched culture and then incubated at $37^{\circ} \mathrm{C}$ till colonies

178 appeared. Lone colonies were picked and streaked aseptically on solid media plates

179 followed by incubation at $37^{\circ} \mathrm{C}$ for 48 hours. Separate colonies were sub-cultured onto

180 nutrient agar plates till pure cultures were obtained. The strains from pure culture were

181 then inoculated into $100 \mathrm{~mL}$ MSM broth which contained $50 \mathrm{mg} / \mathrm{mL}$ of selected pesticides

182 added as the sole source of carbon or phosphorus, or both carbon and phosphorus

183 sources to determine their degradation ability at different time intervals $(2,6,8,12,16$,

$18420,24,30$, and 36 hours) at $30^{\circ} \mathrm{C}$. Negative controls were always run to ensure that 
185 mentioned sources in the media were not contaminated. The measurement of the 186 absorbance was done by using an Agilent Cary 5000 Ultraviolet-to-Visible to-Near187 Infrared (UV-Vis-NIR) spectrophotometer (Agilent Technologies, Petaling Jaya, Malaysia)

188 (Roy et al., 2018). The cultures with the highest degradation ability were stored in glycerol 189 as nutrient-agar slants at $4^{\circ} \mathrm{C}$.

190 Degradation Rate \% $=\frac{\text { Initial OD }- \text { Final OD }}{\text { Initial OD }} \times 100$

\section{Identification and characterization of isolates}

192 The identification and characterization of biodegrading isolates were carried out using 193 morphological, biochemical, and molecular tests. The preserved isolates showing 194 maximum degradation activity were picked and grown on the nutrient medium through 195 spread plate method followed by culturing at $37^{\circ} \mathrm{C}$ for 48 hours as described by Jiang et 196 al., 2019. A phase-contrast microscope Axiovert by (Zeiss model MC-80). was used to 197 examine the colony features as well as the morphological structure of the cells. Then, 198 strains capable of degradation were further tested through gram staining for the 199 identification. The biochemical tests included catalase test, gelatinase test, starch

200 hydrolysis test (amylase test), casein hydrolysis test, oxidase test, Indole production test,

201 Methyl red test, Citrate utilization test, Nitrate reduction test and Urease test.

202

203

204

\section{Molecular characterization}

The isolated strains' DNA was extracted using the Cetyltrimethylammonium Bromide 205 (CTAB) technique (Orek, 2018). The RT PCR (QIAGEN) was used to conduct the $16 \mathrm{~S}$ rDNA amplification process and phylogenetic analysis. The DNA obtained from the isolated strains was utilized as a template for PCR amplification using 16S rDNA primers. The forward primer for the bacterium was FD1 (AGAGTTTGATCCTGGCTCAG 20bp), and the reverse primer was $\mathrm{PP} 1$ (ACGG(ACT)TACCTTGTTACGACTT, 23bp). The PCR products were sequenced by Macrogen Inc., Seoul, Korea. The Basic Local Alignment

211 Search Tool (BLAST) was run to analyze sequences (Altschul et al., 1990). The 16S

212 rRNA gene sequences of selected strains were acquired from GenBank and matched 213 with the gene sequences of our isolates using CLUSTALX. A distance matrix was 214 constructed using the aligned sequences (Jukes and Cantor 1969). Following the 
215 generation of 500 bootstrap sets, MEGA $X$ version 10.2.6 was used to construct a

216 phylogenetic tree using the neighbour-joining technique (Stecher et al., 2020).

217

\section{Growth Rate Study}

219 To check the efficacy of growth of pesticide degrading microbes in MSM broth, the growth 220 curve was observed.

221 In a sterile conical flask holding $100 \mathrm{~mL}$ of $\mathrm{MSM}$ broth, an aliquot $(1 \mathrm{~mL})$ of bacterial 222 suspension was added (Ghanem, Khaled M et al., 2012). The MSM composition (w/v) 223 was $0.1 \% \mathrm{NH}_{4} \mathrm{NO}_{3}, 0.1 \% \mathrm{NaCl}, 0.15 \% \mathrm{~K}_{2} \mathrm{HPO}_{4}, 0.05 \% \mathrm{KH}_{2} \mathrm{PO}_{4}, 0.01 \% \mathrm{MgSO}_{4} .7 \mathrm{H} 2 \mathrm{O}$, $2240.0025 \%$ FeSO4, 1\% glucose and incubated in a shaking incubator at $150 \mathrm{rpm}$ using 225 WiseCube Fuzzy System (model WIS-20) (Al-Thukair \& Malik, 2016) at various 226 temperatures $\left(15^{\circ} \mathrm{C}, 30^{\circ} \mathrm{C}\right.$ and $45^{\circ} \mathrm{C}$ ). The wavelength was set at $600 \mathrm{~nm}$ (OD600) to 227 check cell density at different time intervals $(2,6,8,12,16,20,24,30$ and 36 hours) using 228 an Agilent Cary 5000 Ultraviolet-to-Visible to-Near-Infrared (UV-Vis-NIR) 229 spectrophotometer (Agilent Technologies, Petaling Jaya, Malaysia). The optimum pH of 230 the growth media was adjusted to $\mathrm{pH} 7$. The growth curve was constructed by determining 231 the optimum culture time of each biodegrading strain at different temperature. All the 232 experiments were done in triplicate, and a negative control with no microbial inoculation 233 was carried under the identical circumstances.

\section{Statistical Analysis}

235 The normality of the data was tested using the Pearson's correlation tests for all of the 236 data obtained. Statistical analysis was done using MS Excel 16.0.

237 Approval of field permit

238 Field experiments were approved by Research committee of the University of Agriculture 239 Peshawar, Pakistan (Project number :27/FCPS/AUP) and National institute of 240 biotechnology and genetic engineering (NIBGE), Faisalabad-Pakistan.

\section{Isolation of pesticide-degrading bacteria}


245 Through enrichment, many indigenous pesticide-tolerant bacteria with pesticides as their 246 only carbon source were identified from contaminated soil and industrial effluents. From

247 these enrichment cultures, 20 morphologically diverse strains were isolated on nutrient 248 agar plates containing DDT and aldrin and malathion pesticides, respectively. These 249 strains' pesticide degradation ability was checked on MSM agar plates containing 250 pesticides $(50 \mathrm{mg} / \mathrm{mL})$. The six bacterial isolates used in the degradation experiments.

251 Isolates $1 \mathrm{~A}, 2 \mathrm{~B}$, and $3 \mathrm{C}$ came from soil contaminated with DDT (from Industrial city 252 Faisalabad). While isolates $4 \mathrm{D}, 5 \mathrm{E}$ and $6 \mathrm{~F}$ were from the industrial area of Lahore, 253 Pakistan, with DDT, aldrin and malathion contamination. Of the two locations 254 investigated, samples from the Lahore industrial area had the highest contamination. 255 Pesticide contamination was found in all the soils and effluents utilized to isolate 256 microorganisms. All six isolates were correctly identified using 16S rRNA sequencing.

257 The strain Pseudomonas was found to be the most common among the isolates.

\section{Pesticide degradation activity}

259 Out of 20 bacterial strains from the industrial wastes, only six (1A, 2B, 3C, 4D, 5E and 260 6F) showed significant degradation against all three pesticides at $50 \mathrm{mg} / \mathrm{mL}$, which was 261 tested. The plates were marked into small segments. The zone of degradation was plotted 262 against the periodic time intervals shown in Figures 1, 2 and 3 for the pesticides.

263 The percentage degradation of DDT pesticide was plotted against time. The isolates $1 \mathrm{~A}$, $2642 \mathrm{~B}, 3 \mathrm{C}$ and 4D showed highest degradation activity of $70-80 \%$ during the 36 hours while $2655 \mathrm{E}$ and $6 \mathrm{~F}$ degraded $28-36 \%$ of the same DDT concentration (Figure 1 and Table S1).

267 Figure 1. Graphical representation of percent DDT degradation shown by each bacterial 268 isolate plotted against time. The experiment was done in triplicate, and errors bars 269 indicate the standard deviation.

271 In the case of aldrin, a little variation in percentage values of degradation was observed 272 when plotted against time (Figure 2 and Table S2). The isolate $3 \mathrm{C}$ showed the highest 273 degradation (78\%) against aldrin, followed by $2 \mathrm{~B}$ and $4 \mathrm{D}$ with $72 \%$ and $68 \%$, respectively. 274 In contrast, isolate $1 \mathrm{~A}$ showed $58 \%$ degradation. The degradation values for the isolates 
$2755 \mathrm{E}$ and $6 \mathrm{~F}$ were $30 \%$ and $40 \%$, respectively. However, $5 \mathrm{E}$ and $6 \mathrm{~F}$ values were observed

276 to be lower than $1 \mathrm{~A}, 2 \mathrm{~B}, 3 \mathrm{C}$ and $4 \mathrm{D}$.

277

278 Figure 2. Graphical representation of percent aldrin degradation shown by each bacterial 279 isolate plotted against time. The experiment was done in triplicate, and errors bars 280 indicate the standard deviation.

282 In the case of malathion, a reverse trend was observed, and highest values of $54 \%$ and $28353 \%$ were recorded from $\mathrm{F} 6$ and $\mathrm{E} 5$ isolates over $1 \mathrm{~A}, 2 \mathrm{~B}, 3 \mathrm{C}, 4 \mathrm{D}$, where degradation rate was recorded between $30-40 \%$, as shown in Figure 3 and Table S3.

Figure 3. Graphical representation of percent malathion degradation shown by each bacterial isolate plotted against time. The experiment was done in triplicate, and errors bars indicate the standard deviation.

289

290

291

292

293

294

295

296

297

298

299

300

301

\section{2}

303

304

Overall degradation of the selected bacterial isolates showed that selected locally collected bacteria could easily degrade organophosphates and organo-chlorines. However, the degradation rate can depend on both the type of bacteria and the pesticide composition, which needs to be explored further. These strains could play a useful role in achieving the safe recovery of polluted sites, particularly in a situation where pesticides, chemicals and other undesired toxic substances containing organochlorine and organophosphates and their variety of derivatives might persist. These isolates might also be helpful to produce beneficial microbes sensitive to such toxicities. However, the isolated strains had varying effectiveness for specific pesticides. This trend showed that strains might be applied according to the nature of pollutant present in a particular environment for eradicating toxic chemicals.

\section{Identification and characterization of isolates}

The bacterial strains were selected by analyzing their morphology and colony characteristics, indicating the microbial diversity present in the respective collected 
305 (environmental) samples. Based on the isolates' physical appearance, the distinguishing

306

307

308

309

310

311

312

313

314

315

316

317

318

319

320

321

322

323

324

325

326

327

328

329

330

331

332

333

334

335

yellow, cream, and white pigmented colonies (Fig. 4), a colonial diversity (raised and flat) was observed. When viewed under a phase-contrast microscope, the isolates were appeared with different cellular morphologies. All isolates were mostly rod-shaped, while the isolate 4D exhibited coccus shape as well. Similarly, all isolates were gram-negative and motile except 4D, which is non-motile. None of the isolates contained endospores, and none of the isolates indicated exospores. The isolates $4 \mathrm{D}, 5 \mathrm{E}$ and $6 \mathrm{~F}$ were circular, while the rest are irregular in shape. The isolates $2 \mathrm{~B}, 3 \mathrm{C}$, and $4 \mathrm{D}$ have undulated colony margins whereas $1 \mathrm{~A}, 5 \mathrm{E}$ and $6 \mathrm{~F}$ had entire margins (Table 1). The selected isolates' cell size was found to be $1.5 \mu \mathrm{m}$ for $1 \mathrm{~A}$ and $4 \mathrm{D}$, while the rest of the isolates' cell size ranges from 2.0 to $3 \mu \mathrm{m}$, as presented in Table 1 .

Figure 4. The appearance of colonies of the bacterial isolates 1A, 2B, 3C, 4D, 5E and $6 \mathrm{~F}$ on nutrient agar.

Table 1. Cellular characteristics of biodegrading pesticide isolates

\section{PCR method for 16S rRNA amplification and Sequencing}

Before sequencing all the DNA samples were amplified under optimized conditions. To obtain a PCR product of 1,500 base pairs, universal eubacterial rDNA primers fD1 and rP1 were used (Figure S1). Purified PCR product was sequenced commercially. A partial sequence of the 16S rRNA showed that four isolates had 97-99 \% homology with Pseudomonas spp. Simultaneously, the other two isolates were 97 and $96 \%$ identical to Actinobacter baumannii and Acidothiobacillus ferroxidans, respectively (Table 2).

All these sequences are deposited in the National Center for Biotechnology Information (NCBI) (https://www.ncbi.nlm.nih.gov/).

Table 2. Sequence identity (\%) of the partial 16S rRNA gene sequence of isolates obtained from environmental samples with related microbes

\section{Phylogenetic Analysis}


336 Partial 16S rRNA were obtained from the NCBI (www.ncbi.nIm.nih.gov) web site, and they 337 were aligned with our isolates to generate a phylogenetic tree (Figure 5). Phylogenetic 338 analysis showed that all five isolates have evolved from a common ancestor. They have 339 a close relationship among themselves except $5 \mathrm{E}$ which shares a common ancestor but 340 is far off from the other isolates in the tree. This showed the diversity among the isolates 341 persists that can tolerate pesticides even at high concentration.

342 Figure 5. Phylogenetic tree showing evolutionary relationships of various strains. The 343 Neighbor-Joining technique was used to infer the evolutionary history. MEGA X version 344 10.2.6 was used to undertake the evolutionary analyses (Kumar S., 2018; Stecher et al., 345 2020).

\section{Estimation of bacterial growth rate}

At $600 \mathrm{~nm}$, optical density of each isolate was recorded at various intervals i.e., 2, 8, 12, $16,20,24,30$ and 36 hours, on MSM medium. All the isolates studied in the experiment attained an OD of around 0.7 in broth at $30{ }^{\circ} \mathrm{C}$ after 8 hours, while it took more than 10 hours to reach the OD of 0.7 at other temperatures, so the optimal temperature for these strains was $30^{\circ} \mathrm{C}$, as shown in Figure 6 and Table S1. $6 \mathrm{~F}$ showed maximum growth at different temperatures among all the isolates, while A1 showed the least. Similar results were reported by Kaya et al., in 2014 and Murad et al. in 2007.

Figure 6. Growth curve of isolated strains $1 \mathrm{~A}, 2 \mathrm{~B}, 3 \mathrm{C}, 4 \mathrm{D}, 5 \mathrm{E}$ and $6 \mathrm{~F}$ at $15^{\circ} \mathrm{C}, 30^{\circ} \mathrm{C}$ and 358 $45^{\circ} \mathrm{C}$. The black bars represent standard error.

359

\section{Discussion}

361 The study addresses the isolation and identification of bacteria residing in pesticidepolluted sites. We also observed the extent of bacterial chemical utilization capacity for DDT, aldrin, and malathion. The identification of isolated bacteria was governed by analyzing both phenotypic and genotypic traits. From the current study, microbial biodiversity present in industrial waste was assessed using 16S rRNA analysis which is by far the best genetic marker that could exquisitely identify and illustrate 
367 the evolutionary relationship of mixed cultures of environmental and clinical bacterial 368 isolates (Jovel et. al., 2016 and Lagier et al., 2015).

369 In this study, six novel strains were found to have distinct degradation abilities for the 370 three pesticides DDT, aldrin, and malathion. All the isolates used these pesticides as the sole carbon and energy source (Rani et al., 2018). The optical density was relatively increasing at the same rate as within the nutrient medium. (Figure 1).

373 The $P$. aeruginosa strains $1 \mathrm{~A}$ and $4 \mathrm{D}$ showed the highest degradation percentage of about $80 \%$ for DDT. Strains $3 \mathrm{C}$ and $4 \mathrm{D}$ of $P$. aeruginosa also successfully degraded up to $70 \%$ of $50 \mathrm{mg} / \mathrm{mL}$ DDT as shown in Figure 1 . The $P$. aeruginosa strain has good potential for biodegradation of DDT, also observed in the study done by Sariwati et al., (2018), where $P$. aeruginosa degraded $90 \%$ of $5 \mathrm{mM} \mathrm{DDT} \mathrm{(1.7} \mathrm{mg} / \mathrm{mL})$, a smaller amount as compared to the current study. In another degradation study, Wu et al., 2018 (Wu et al., 2018) identified P. aeruginosa NBRC 3080 and Bacillus subtilis NBRC 3009 degraded about $65.97 \%$ and $86.44 \%$ respectively of $5 \mathrm{mM}$ DDT in 7 days, which was quite similar to our findings. Moreover, other microbes like Serratia marcescens NCIM 2919 and Fomitopsis pinicola also degraded 42\% DDT in 10 and 7 days of incubation while $P$. aeruginosa addressed in this study utilized pesticide and degraded it in 36 hours of incubation (Grewal, J. and Bhattacharya 2016; Sariwati et al., 2017; Sariwati and Purnomo, 2018; Rizqi et al., 2021). This indicates that the strains reported here have a rapid rate of DDT degradation, which could be increased further by the synergic effect of two similar or different species.

For aldrin, all the $P$. aeruginosa strains showed significant activity. The degradation percentage given by $P$. aeruginosa strains $1 \mathrm{~A}, 2 \mathrm{~B}, 3 \mathrm{C}, 4 \mathrm{D}$, i.e., $58 \%, 72 \%$, $78 \%$ and $68 \%$, respectively, is shown in Figure 2. Lately, no evidence of aldrin degradation was observed by $P$. aeruginosa. However, other microbes like $P$.

392 fluorescens, White-Rot Fungus (Pleurotus ostreatus), and Paenibacillus sp.

393 IITISM08 have shown the best degradation ability with percentages of $94.8 \%$ (conc.

$39410 \mathrm{mg} / \mathrm{L}$ ), $100 \%$ (conc. $5 \mathrm{mM}$ ) and $79 \%(50 \mu \mathrm{g} / \mathrm{mL}$ ), respectively but utilized less

395 concentration as compared to recent isolates that explain the decent activity of our 396 strains (Purnomo et al., 2017, Rani et al., 2018). 
397 Aldrin and DDT both are organochlorine pesticides, and it was noticed that all the $P$.

398 aeruginosa strains had got reductive de-chlorination ability; therefore, they efficiently 399 degraded these difficult compounds (Chen et al., 2013). It is also stated that $P$. aeruginosa 400 possesses hydroxylase enzymes, like oxygenases and reductases, which play their part 401 during the process of degradation (Hamdan et al., 2021). DDT is normally metabolized to 402 DDD, DDE, alkane and cycloalkene. But the recent study could not provide the 403 metabolites of degradation. Pseudomonas species are also known for the production of 404 biosurfactant, which apparently caused its increased rate of degradation as compared to 405 other isolates (Sariwati et al., 2018). That might imply their role in malathion degradation 406 to the extent of $30-40 \%$. These observations indicate that $P$. aeruginosa maintains genetic 407 diversity and metabolic flexibility, a phenomenon also addressed by Chanika et al., 2011 408 (Chanika et al., 2011).

409 Malathion is an organophosphate pesticide and was degraded efficiently by isolates

410 A. baumannii (53\%) and A. ferroxidans (54\%), as shown in Figure 3. A similar study 411 was done by Kadhim et al., (2015) where Pseudomonas putida degraded $47.18 \%$ 412 a n d Staphylococcus vitulinus $44.24 \%$ in ten days. In contrast, our findings were 413 somewhat similar but were prime in terms of degradation rate. In 2016, Khan et al. 414 identified Bacillus licheniformis, which utilized malathion as the sole carbon source 415 and degraded up to $78 \%$ within 5 days efficiently (Kadhim et al., 2015, Khan et al., 2016).

416 Whereas in our study, the best degradation percentage was about $54 \%$ which is less than 417 the preceding study, but if the time of degradation is exceeded it might show a better 418 result. Malathion, being an organophosphate pesticide, contains phosphorus-ester bonds 419 (P-S bond), which usually proves to be hydrolyzed by esterases and organophosphorus 420 hydrolases. It is observed that esterase is of great importance when microbes use 421 malathion as a sole carbon source. Synthetic pyrethroids like permethrin and malathion 422 are normally used against garden pests. In a previous study, A. baumannii strain ZH-14 423 promotes $100 \%(50 \mathrm{mg} / \mathrm{mL})$ degradation of permethrin in 72 hours by using a similar 424 method (Zhan, $\mathrm{H}$ et al. 2018). Co-resistance against both malathion and permethrin is 425 shown by many pests which control unique esterases(Francis et al., 2017).

426 The current study showed that $A$. baumannii and Acidothiobacillus ferroxidans utilized 427 malathion as a sole carbon source, which indicates that both the strains may contain 
428 enzyme esterases which could break it down to acceptable metabolites. Furthermore, it 429 is noteworthy that $A$. ferroxidans is mainly involved in bioleaching of elements like sulphur, 430 iron, copper, and heavy metals from waste material. The effective biodegradation of 431 malathion by the strain also implies its capability to utilize phosphate-esters (Pankaj et 432 al., 2021). A. baumannii and $A$. ferroxidans also degraded DDT and aldrin to the extent of $43328-40 \%$. Thus, we infer dynamic catalytic activity in all the isolates with variable degradation 434 rate depending upon pesticide composition, which needs to be explored further.

435 The current study provides six microbes with varying degradation ability. Almost all the 436 preceding studies highlighted showed degradation at $30^{\circ} \mathrm{C}$ in about 7 to 10 days of 437 incubation, whereas the current study identified microorganisms with a higher degradation 438 ability at the same temperature in 36 hours. This could be because these organisms were 439 isolated from pesticide polluted lands and waters, therefore, were more thoroughly 440 adapted. This trend showed that particular strains might be applied according to the 441 nature of pollutant present in a specified environment for eradicating toxic chemicals. 442 Limitations of the study

443 Our findings' scope can be further improved by considering the other factors such as 444 organic matter, $\mathrm{pH}$, temperature etc., that might help to pace the specific microbes' 445 availability for biodegradation and their interactive association with chemicals.

446 Moreover, the study fails to address the extent of degradation of DDT, aldrin, and 447 malathion: whether to their intermediate compounds or a more complete degradation. 448 Furthermore, the enzymes contributing to the degradation ability should be isolated and studied. These deficiencies provide a topic for further investigators in this regard.

\section{Conclusion}

452 Current study found that among all the six strains isolated from polluted pesticide 453 environment, two strains of $P$. aeruginosa (1A and 4D) have shown higher potential ability 454 to degrade $80 \%$ of DDT, and $P$. aeruginosa 3C showed the highest degradation 455 percentage, i.e., $78 \%$ for aldrin whilst in the case of malathion $A$. baumannii and $A$. 456 ferroxidans have shown considerable degradation percentages of $53 \%$ and $54 \%$ 457 respectively. 


\section{Conflict of interest}

461 The authors note no conflicts of interest for the editorial process, the corresponding author 462 is the only contact person and is responsible for communicating with the other authors 463 about progress, submissions of revisions and final approval of proofs.

464

\section{Supplementary Data}

466 The data show the statistical analysis of biodegrading microbes against three pesticides 467 (DDT, aldrin and malathion). Table S1 shows the biodegradation analysis of microbes 468 against DDT; Table S2 shows the biodegradation analysis of microbes against aldrin; 469 Table S3 shows the biodegradation analysis of microbes against malathion; and Table 470 S4 shows growth curves of the biodegrading bacteria in MSM broth.

471 Funding Statement

472 The research was supported by University of Agriculture Peshawar; KPK-Pakistan and 473 samples were provided by the National Institute of Biotechnology and Genetic 474 Engineering (NIBGE) Faisalabad-Pakistan.

475

476

477 NA devised methodology, did all the experiments, and wrote original draft preparations. $\mathrm{MH}$ contributed to concept development and data curation, FS has done the phylogenetic analysis, analyzed the data statistically and prepared the figures. $\mathrm{HN}$ contributed to the final writing of the manuscript. and NS contributed to the data collections. SK contributed to the manuscript preparation and finalization. The final paper has been reviewed and

\section{3} approved by all the co-authors.

484 This work was supported by the University of Azad Jammu and Kashmir Muzaffarabad, 485 Pakistan and Shaheed Benazir Bhutto Women University, Peshawar Pakistan. The 486 research was supported by University of Agriculture Peshawar; KPK-Pakistan and 487 samples were provided by the National Institute of Biotechnology and Genetic 488 Engineering (NIBGE) Faisalabad-Pakistan, University of Sheffield UK, and Islamia 
489 College University Peshawar Pakistan. The manuscript was proof-read by Prof Mike P

490 Williamson from the University of Sheffield UK.

491

492

493

494

495

496

497

498

499

500

501

502

503

504

505

506

507

508

509

510

511

512

513

514

515

516

\section{REFERENCES}

Altschul, S. F.; Gish, W.; Miller, W.; Myers, E. W.; Lipman, D. J. Basic Local Alignment Search Tool. J. Mol. Biol. 1990, 215, 403-410. https://doi.org/10.1016/S00222836(05)80360-2.

Arrebola, J. P.; Belhassen, H.; Artacho-Cordón, F.; Ghali, R.; Ghorbel, H.; Boussen, H.; Perez-Carrascosa, F. M.; Expósito, J.; Hedhili, A.; Olea, N. Risk of Female Breast Cancer and Serum Concentrations of Organochlorine Pesticides and Polychlorinated Biphenyls: A Case-Control Study in Tunisia. Sci. Total Environ. 2015, 520, 106-113. https://doi.org/10.1016/j.scitotenv.2015.03.045.

Arora, P. K.; Srivastava, A.; Garg, S. K.; Singh, V. P. Recent advances in degradation of chloronitrophenols. Bioresource Technology, 250 (2017), 902-909. https://doi:10.1016/j.biortech

Al-Thukair.; Assad Ahmed.; Karim Malik. Pyrene metabolism by the novel bacterial strains Burkholderia fungorum (T3A13001) and Caulobacter sp (T2A12002) isolated from an oil-polluted site in the Arabian Gulf. International Biodeterioration \& Biodegradation, 2016,110, 32-37. https://doi.org/10.1016/j.ibiod.2016.02.005.

Bhatt, P.; Bhatt, K.; Sharma, A.; Zhang, W.; Mishra, S.; Chen, S.; Biotechnological basis of microbial consortia for the removal of pesticides from the environment. Critical Reviews in Biotechnology, 2020, 1-22.

Bhatt P.; Gangola S.; Bhandari G.; Zhang W.; Maithani D.; Mishra S.; Chen S. New insights into the degradation of synthetic pollutants in contaminated environments. Chemosphere, 2020, 30:128827.

Bhatt, P.; Joshi, T.; Bhatt, K.; Zhang, W.; Huang, Y.; Chen, S. Binding interaction of glyphosate with glyphosate oxidoreductase and C-P lyase: Molecular docking and 
517

518

519

520

521

522

523

524

525

526

527

528

529

530

531

532

533

534

535

536

537

538

539

540

541

542

543

544

545

546

molecular dynamics simulation studies. Journal of Hazardous Materials, 409, 2020, 124927. https://doi.org/10.1016/j.jhazmat.2020.124927

Bhatt, P.; Verma, A.; Gangola, S.; Bhandari, G.; Chen, S. Microbial glycoconjugates in organic pollutant bioremediation: recent advances and applications. Microbial Cell Factories, 2021, 20(1), 1-18. https://doi.org/10.1186/s12934-021-01556-9

Birolli, W. G.; Lima, R. N.; \& Porto, A. L. M. Applications of marine-derived microorganisms and their enzymes in biocatalysis and biotransformation, the underexplored potentials. Frontiers in Microbiology, 2019, 10(AUG). https://doi.org/10.3389/fmicb.2019.01453

Chanika, E.; Georgiadou, D.; Soueref, E.; Karas, P.; Karanasios, E.; Tsiropoulos, N. G.; Tzortzakakis, E. A.; Karpouzas, D. G. Isolation of Soil Bacteria Able to Hydrolyze Both Organophosphate and Carbamate Pesticides. Bioresour. Technol. 2011, 102 (3), 3184-3192. https://doi.org/10.1016/j.biortech.2010.10.145.

Chen, M.; Cao, F.; Li, F.; Liu, C.; Tong, H.; Wu, W.; Hu, M. Anaerobic Transformation of DDT Related to Iron (III) Reduction and Microbial Community Structure in Paddy Soils. J. Agric. Food Chem. 2013, 61 (9), 2224-2233. https://doi.org/10.1021/jf305029p.

Cycoń M.; Mrozik A.; Piotrowska-Seget Z.; Bioaugmentation as a strategy for the remediation of pesticide-polluted soil: A review. Chemosphere. 2017 Apr 1; 172:52-71.

Farhan, M.; Khan, A. U.; Wahid, A.; Ahmad, M.; Ahmad, F. Biodegradation of Chlorpyrifos Using Indigenous Pseudomonas Sp. Isolated from Industrial Drain. Pakistan J. Nutr. 2012, $11 \quad$ (12), $1183-1189$. https://doi.org/10.3923/pjn.2012.1183.1189.

Francis, S.; Saavedra-Rodriguez, K.; Perera, R.; Paine, M.; Black IV, W.C.; Delgoda, R. Insecticide resistance to permethrin and malathion and associated mechanisms in Aedes aegypti mosquitoes from St. Andrew Jamaica. PLoS One, 2017. 12(8), p.e0184387.

Ghanem, I.; Orfi, M.; Shamma, M. Biodegradation of Chlorpyrifos by Klebsiella Sp. Isolated from an Activated Sludge Sample of Waste Water Treatment Plant in 
547

548

549

550

551

552

553

554

555

556

557

558

559

560

561

562

563

564

565

566

567

568

569

570

571

572

573

574

575

576

577

Damascus. Folia Microbiol. (Praha). 2007, 52 (4), 423-427. https://doi.org/10.1007/BF02932098.

Ghanem, Khaled M.; Fahad A. Al-Fassi; Abdulghafoor K. Biag. Optimization of methyl orange decolorization by mono and mixed bacterial culture techniques using statistical designs. African Journal of Microbiology Research, 2012, 6(2): 436-446. https://academicjournals.org/journal/AJMR/article-abstract/1E0A67440355

Grewal, J.; Bhattacharya, A.; Kumar, S.; Singh, D. K.; Khare, S. K. Biodegradation of 1,1,1-Trichloro-2,2- Bis (4-Chlorophenyl) Ethane (DDT) by Using Serratia Marcescens NCIM 2919. J. Environ. Sci. Heal. Part B 2016, 51 (12), 809-816. https://doi.org/10.1080/03601234.2016.1208455.

Huang, Y.; Zhang, W.; Pang, S.; Chen, J.; Bhatt, P.; Mishra, S.; Chen, S. Insights into the microbial degradation and catalytic mechanisms of chlorpyrifos. Environmental Research, 194, 2020, 110660. https://doi.org/10.1016/j.envres.2020.110660.

Jayaraj R.; Megha P.; Sreedev P. Organochlorine pesticides, their toxic effects on living organisms and their fate in the environment. Interdiscip Toxicol. 2016, 9(3-4):90. https://doi.org/10.1515/intox-2016-0012.

Jiang, J.; Tang, M.; Chen, J.; Yang, Y. Identification and Degradation Characteristics of Bacillus Cereus Strain WD-2 Isolated from Prochloraz-Manganese-Contaminated Soils. PLoS One, 2019, $14 \quad$ (8), e0220975. https://doi.org/10.1371/journal.pone.0220975.

Jovel, J.; Patterson, J.; Wang, W.; Hotte, N.; O’Keefe, S.; Mitchel, T.; Perry, T.; Kao, D.; Mason, A. L.; Madsen, K. L.; Wong, G. K. S. Characterization of the Gut Microbiome Using 16S or Shotgun Metagenomics. Front. Microbiol. 2016, 7. https://doi.org/10.3389/fmicb.2016.00459.

Jukes, T. H.; Cantor, C.R. Evolution of protein molecules. Mammalian protein metabolism, 1969; 3, 21-132.

Kadhim, F.; Rabee, A. M.; Abdalraheem, E. Biodegradation of Malathion by Selected Bacterial Isolates. J. Int. Environ. Appl. Sci. 2015, 10 (3), 361-366.

Kaya, T.; Aslim, B.; Kariptaş, E. Production of Biosurfactant by Pseudomonas Spp. Isolated from Industrial Waste in Turkey. Turkish J. Biol. 2014, 38 (3), 307-317. https://doi.org/10.3906/biy-1303. 
578

579

580

581

582

583

584

585

586

587

588

589

590

591

592

593

594

595

596

597

598

599

600

601

602

603

604

605

606

607

608

Khan, S.; Zaffar, H.; Irshad, U.; Ahmad, R.; Khan, A. R.; Shah, M. M.; Bilal, M.; Iqbal, M.; Naqvi, T. Biodegradation of Malathion by Bacillus Licheniformis Strain ML-1. Arch. Biol. Sci. 2016, 68 (1), 51-59. https://doi.org/10.2298/ABS141218007K.

Kim, K. H.; Kabir, E.; Jahan, S. A. Exposure to Pesticides and the Associated Human Health Effects. Sci. Total Environ. 2017, 575, 525-535. https://doi.org/10.1016/j.scitotenv.2016.09.009.

Kumar, S.; Kaushik, G.; Dar, M. A.; Nimesh, S.; López-Chuken, U. J.; Villarreal-Chiu, J. F. Microbial Degradation of Organophosphate Pesticides: A Review. Pedosphere 2018, 28 (2), 190-208. $\quad$ https://doi.org/10.1016/S10020160(18)60017-7.

Lagier, J. C.; Hugon, P.; Khelaifia, S.; Fournier, P. E.; La Scola, B.; Raoult, D. The Rebirth of Culture in Microbiology through the Example of Culturomics To Study Human Gut Microbiota. Clin. Microbiol. Rev. 2015, 28 (1), 237-264. https://doi.org/10.1128/CMR.00014-14.

Mazzoni, M.; Ferrario, C.; Bettinetti, R.; Piscia, R.; Cicala, D.; Volta, P.; Borgå, K.; Valsecchi, S.; Polesello, S. Trophic Magnification of Legacy (PCB, DDT and Hg) and Emerging Pollutants (PFAS) in the Fish Community of a Small Protected Southern Alpine Lake (Lake Mergozzo, Northern Italy). Water 2020, 12 (6), 1591. https://doi.org/10.3390/w12061591.

Mishra S.; Lin Z.; Pang S.; Zhang W.; Bhatt P.; Chen S. Recent advanced technologies for the characterization of xenobiotic-degrading microorganisms and microbial communities. Frontiers in Bioengineering and Biotechnology. 2021 Feb 10;9:31.

Murad, S.; Hasan, F.; Ali Shah, A.; Hameed, A.; Ahmed, S. Isolation of Phthalic Acid Degrading Pseudomonas SP. P1 from Soil. Pakistan J. Bot. 2007, 39 (5), 18331841.

Orek, C. O. An Optimised Cetyltrimethylammonium Bromide (CTAB)-Based Protocol for Extracting RNA from Young and Old Cassava Leaves. Journal of Advances in Biology \& Biotechnology, 2018, 19(4), 1-7. https://doi.org/10.9734/jabb/2018/45370 
609 Purnomo, A. S.; Nawfa, R.; Martak, F.; Shimizu, K.; Kamei, I. Biodegradation of Aldrin

610

611

612

613

614

615

616

617

618

619

620

621

622

623

624

625

626

627

628

629

630

631

632

633

634

635

636 and Dieldrin by the White-Rot Fungus Pleurotus Ostreatus. Curr. Microbiol. 2017, 74 (3), 320-324. https://doi.org/10.1007/s00284-016-1184-8.

Rani, R.; Usmani, Z.; Gupta, P.; Chandra, A.; Das, A.; Kumar, V. Effects of Organochlorine Pesticides on Plant Growth-Promoting Traits of PhosphateSolubilizing Rhizobacterium, Paenibacillus Sp. IITISM08. Environ. Sci. Pollut. Res. 2018, 25 (6), 5668-5680. https://doi.org/10.1007/s11356-017-0940-z.

Regueiro, J.; López-Fernández, O.; Rial-Otero, R.; Cancho-Grande, B.; SimalGándara, J. A Review on the Fermentation of Foods and the Residues of Pesticides-Biotransformation of Pesticides and Effects on Fermentation and Food Quality. Crit. Rev. Food Sci. Nutr. 2015, 55 (6), 839-863. https://doi.org/10.1080/10408398.2012.677872.

Rizqi, H. D.; Purnomo, A. S.; Kamei, I. Interaction and Effects of Bacteria Addition on Dichlorodiphenyltrichloroethane Biodegradation by Daedalea Dickinsii. Curr. Microbiol. 2021. https://doi.org/10.1007/s00284-020-02305-8.

Roy, D. C.; Biswas, S. K.; Saha, A. K.; Sikdar, B.; Rahman, M.; Roy, A. K.; Prodhan, Z. H.; Tang, S. S. Biodegradation of Crystal Violet dye by bacteria isolated from textile industry effluents. PeerJ, 2018 (6), 1-15. https://doi.org/10.7717/peerj.5015

Sariwati, A.; Purnomo, A. S. The Effect of Pseudomonas Aeruginosa Addition on 1,1,1Trichloro-2,2-Bis(4-Chlorophenyl)Ethane (DDT) Biodegradation by Brown-Rot Fungus Fomitopsis Pinicola. Indones. J. Chem. 2018, 18 (1), 75. https://doi.org/10.22146/ijc.25158.

Sariwati, A.; Purnomo, A. S.; Kamei, I. Abilities of Co-Cultures of Brown-Rot Fungus Fomitopsis Pinicola and Bacillus Subtilis on Biodegradation of DDT. Curr. Microbiol. 2017, 74 (9), 1068-1075. https://doi.org/10.1007/s00284-017-1286-y.

Stecher, G.; Tamura, K.; Kumar, S. Molecular Evolutionary Genetics Analysis (MEGA) for MacOS. Mol. Biol. Evol. 2020, 37 (4), 1237-1239. https://doi.org/10.1093/molbev/msz312. 
637 Syed, J. H.; Alamdar, A.; Mohammad, A.; Ahad, K.; Shabir, Z.; Ahmed, H.; Ali, S. M.;

638

639

640

641

642

643

644

645

646

Sani, S. G. A. S.; Bokhari, H.; Gallagher, K. D.; Ahmad, I.; Eqani, S. A. M. A. S. Pesticide Residues in Fruits and Vegetables from Pakistan: A Review of the Occurrence and Associated Human Health Risks. Environ. Sci. Pollut. Res. 2014, 21 (23), 13367-13393. https://doi.org/10.1007/s11356-014-3117-z.

T. Al Hattab, M.; E. Ghaly, A. Disposal and Treatment Methods for Pesticide Containing Wastewaters: Critical Review and Comparative Analysis. J. Environ. Prot. (Irvine,. Calif). 2012, 03 (05), 431-453. https://doi.org/10.4236/jep.2012.35054.

UNEP Listing of POPs in the Stockholm Convention. http://chm.pops.int/TheConvention/ThePOPs/AllPOPs/tabid/2509/Default.aspx. Accessed 10 Apr 2018.

Wu, T.; Xu, J.; Xie, W.; Yao, Z.; Yang, H.; Sun, C.; Li, X. Pseudomonas aeruginosa L10: A hydrocarbon-degrading, biosurfactant-producing, and plant-growthpromoting endophytic bacterium isolated from a Reed (Phragmites australis). Frontiers in Microbiology, 2018, 9 (1), 1-12. https://doi.org/10.3389/fmicb.2018.01087.

Ye, X.; Dong, F.; Lei, X. Microbial Resources and Ecology - Microbial Degradation of Pesticides. Nat. Resour. Conserv. Res. 2018, 1 https://doi.org/10.24294/nrcr.v1i1.242.

Zhan, H.; Wang, H.; Liao, L.; Feng, Y.; Fan, X.; Zhang, L.; and Chen, S. Kinetics and novel degradation pathway of permethrin in Acinetobacter baumannii $\mathrm{ZH}-$ 14. Frontiers in microbiology, 2018,9, 98. 
Figure 1

Graphical representation of percent DDT degradation showed by each bacterial isolate plotted against time.

The experiment was done in triplicate, and errors bars indicates the standard deviation.

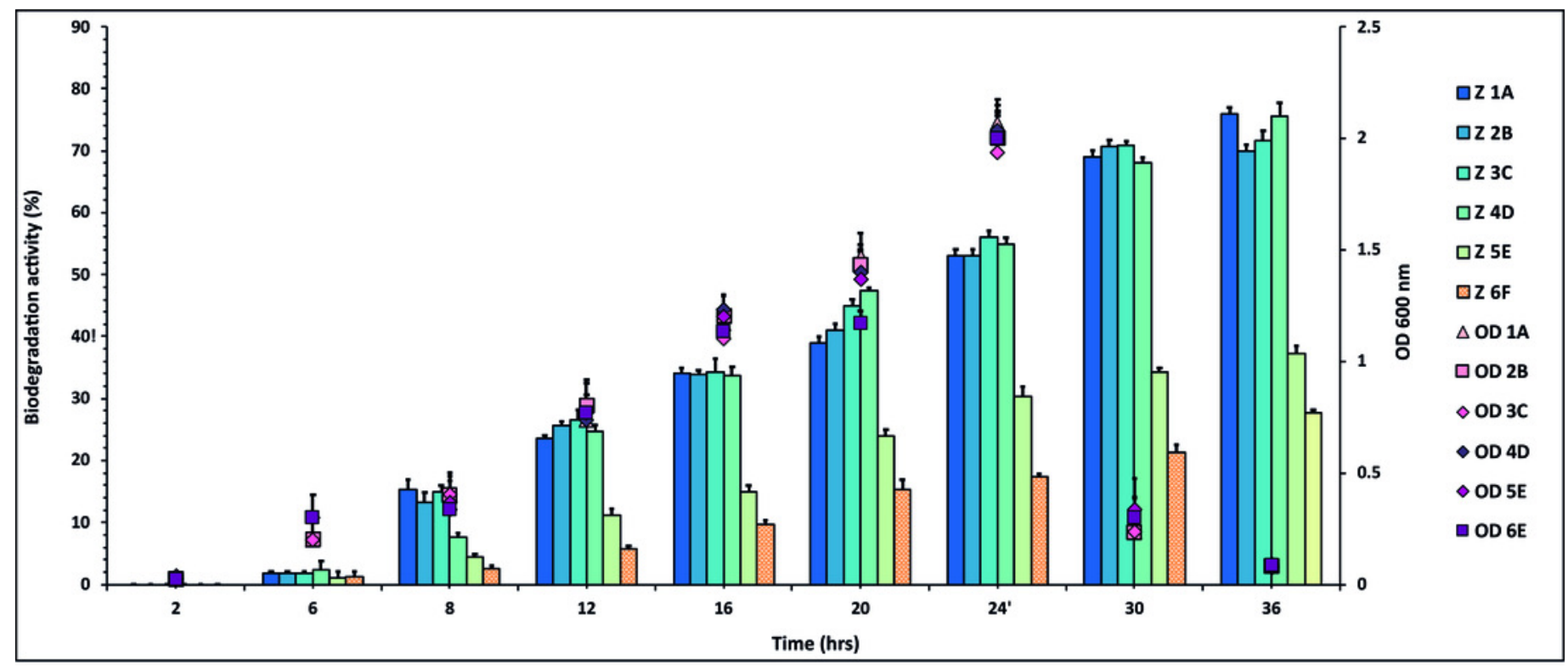


Figure 2

Graphical representation of percent aldrin degradation shown by each bacterial isolate plotted against time.

The experiment was done in triplicate, and errors bars indicates the standard deviation.

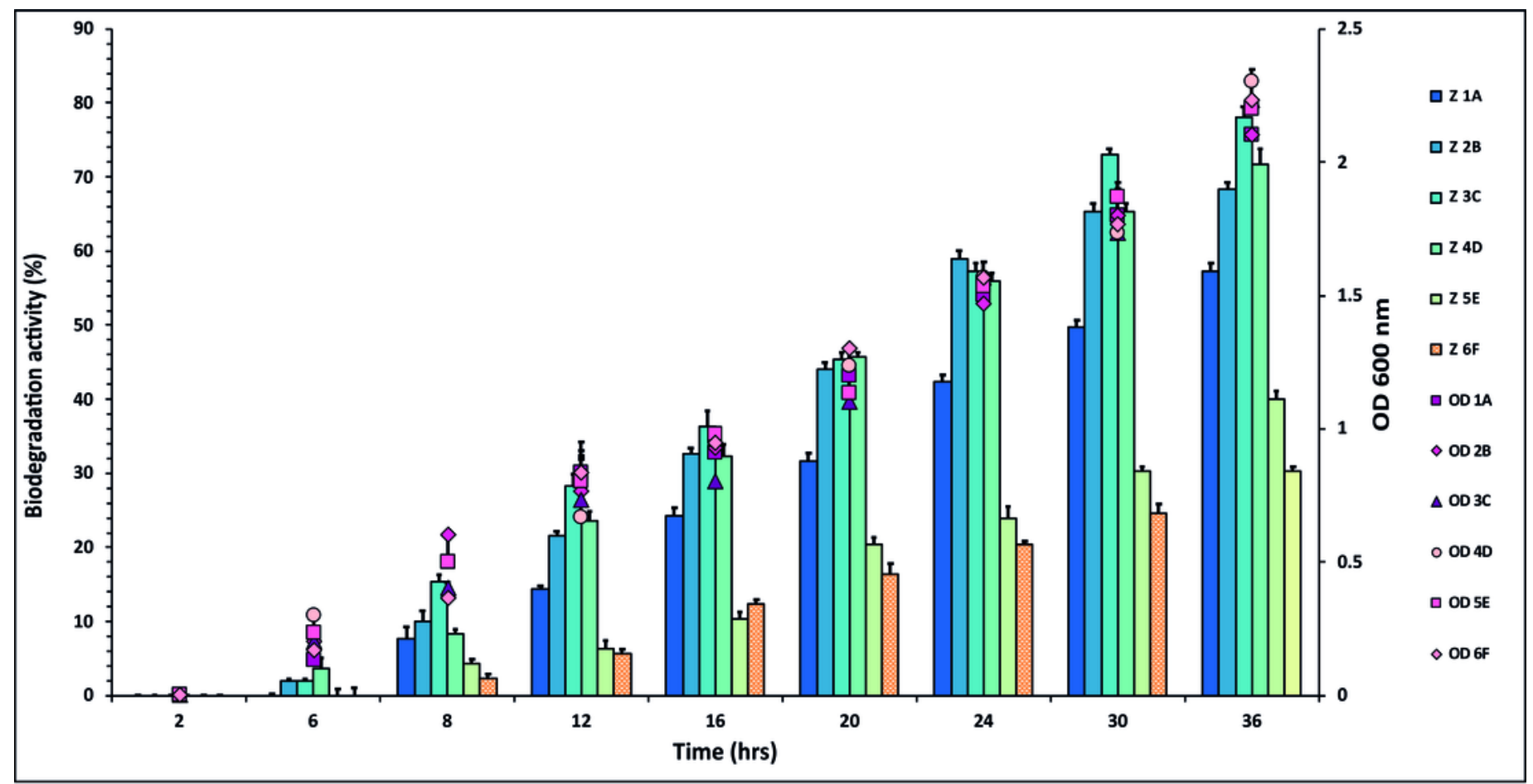


Figure 3

Graphical representation of percent malathion degradation shown by each bacterial isolate plotted against time.

The experiment was done in triplicate, and errors bars indicate the standard deviation.

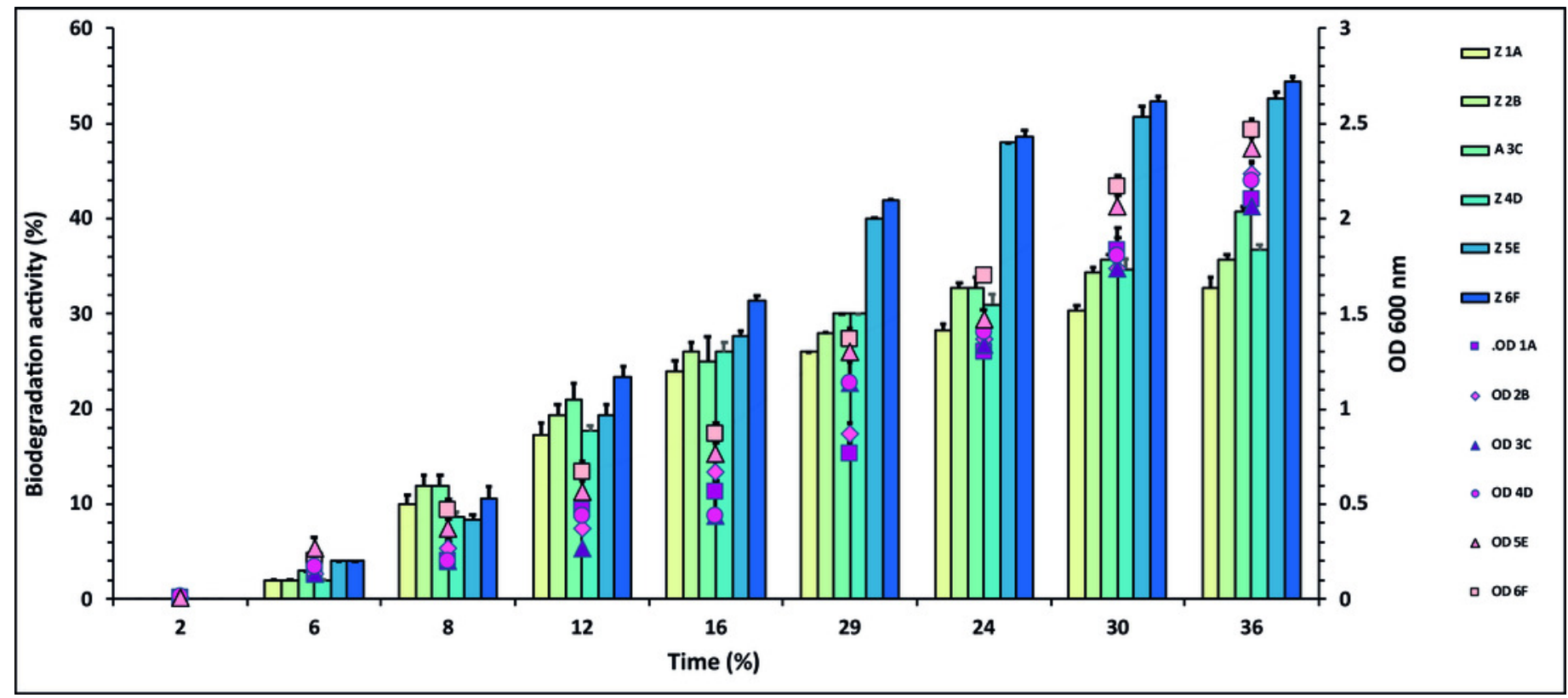




\section{Figure 4}

The appearance of colonies of the bacterial isolates $1 \mathrm{~A}, 2 \mathrm{~B}, 3 \mathrm{C}, 4 \mathrm{D}, 5 \mathrm{E}$ and $6 \mathrm{~F}$ on nutrient agar.

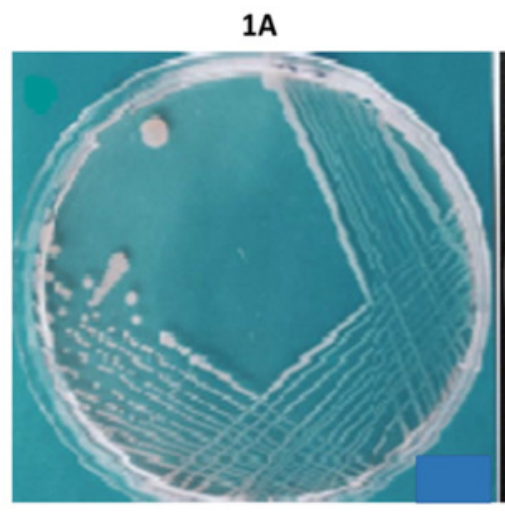

$6 \mathrm{~F}$

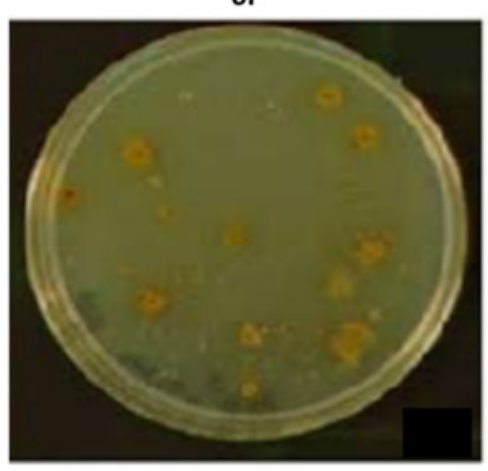

$3 C$

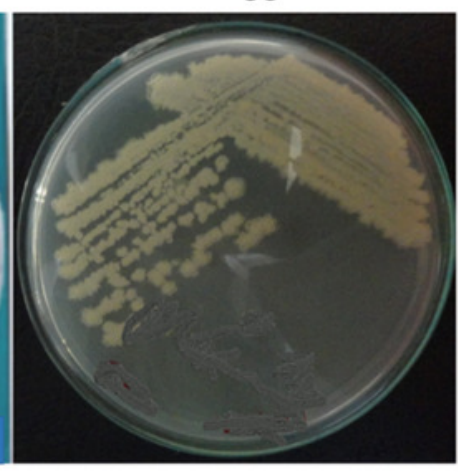

$5 E$

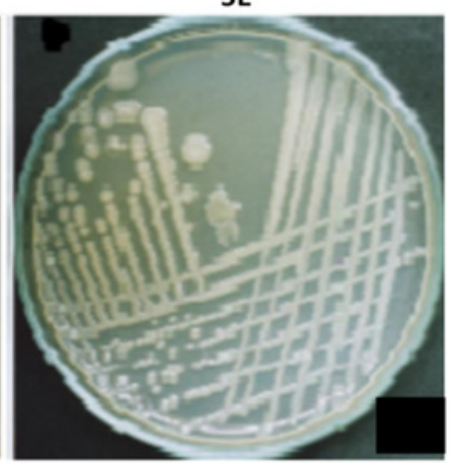

$2 B$

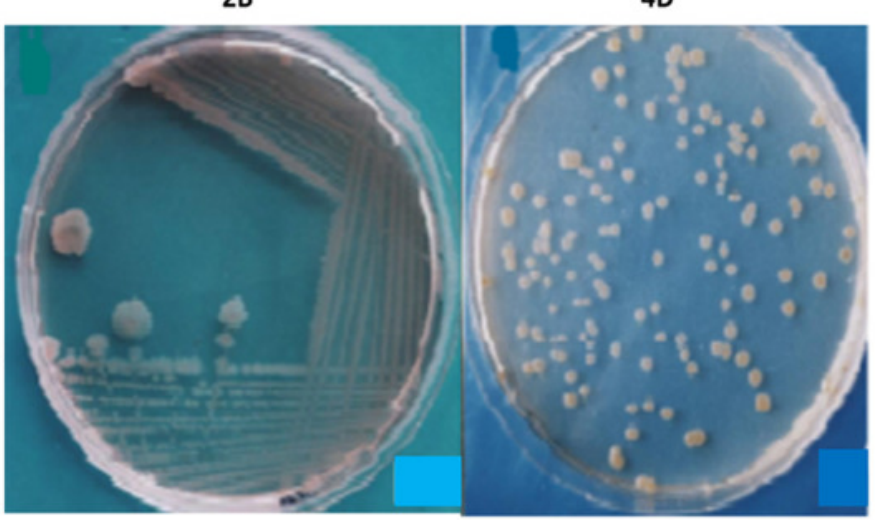


Figure 5

\section{Evolutionary relationships of taxa -The evolutionary history was inferred using the Neighbor-Joining method (Saitou and Nei, 1987).}

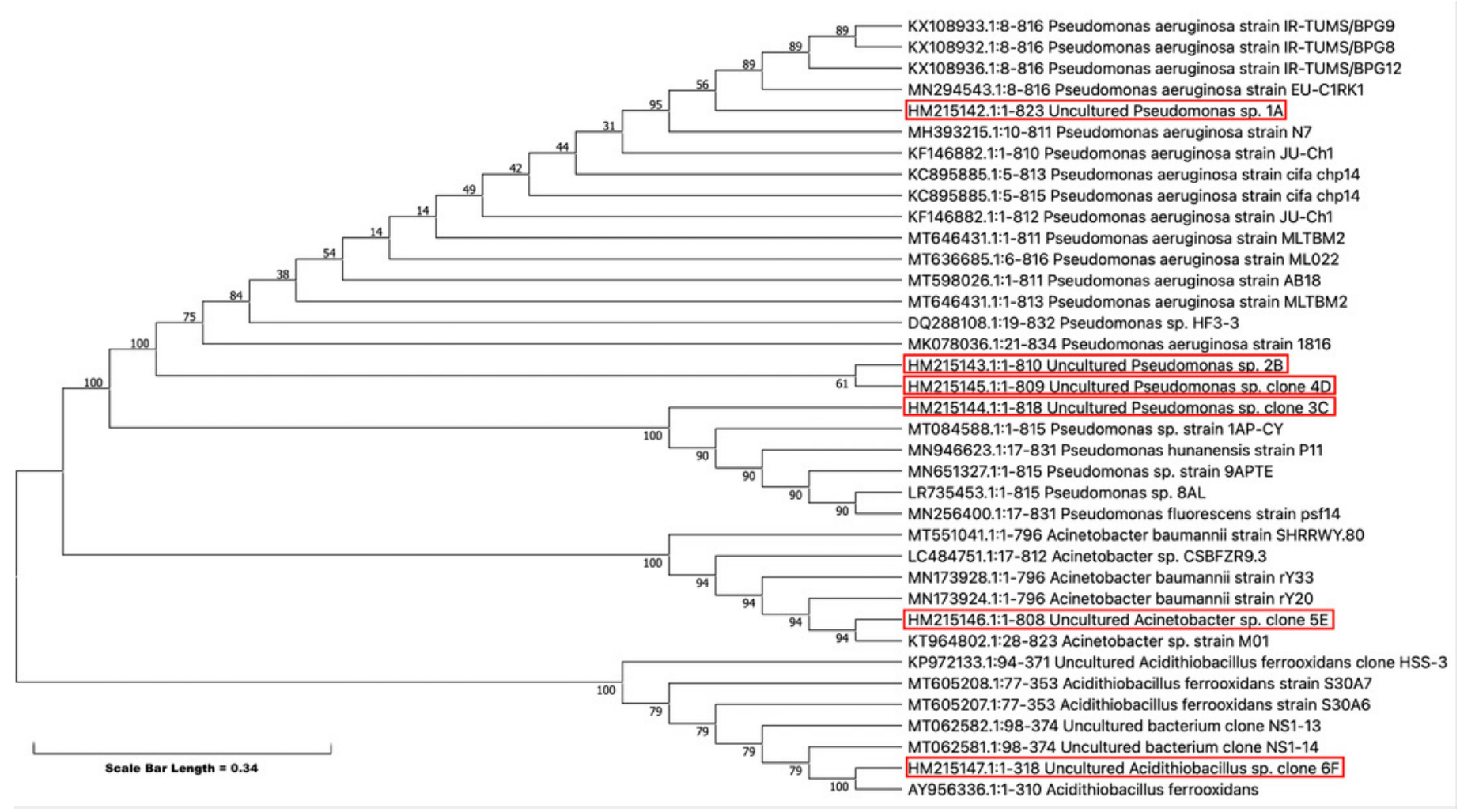


Figure 6

Growth curve of isolated strains $1 \mathrm{~A}, 2 \mathrm{~B}, 3 \mathrm{C}, 4 \mathrm{D}, 5 \mathrm{E}$ and $6 \mathrm{~F}$ at $15^{\circ} \mathrm{C}, 30^{\circ} \mathrm{C}$ and $45^{\circ} \mathrm{C}$.

The black bars represent standard error.
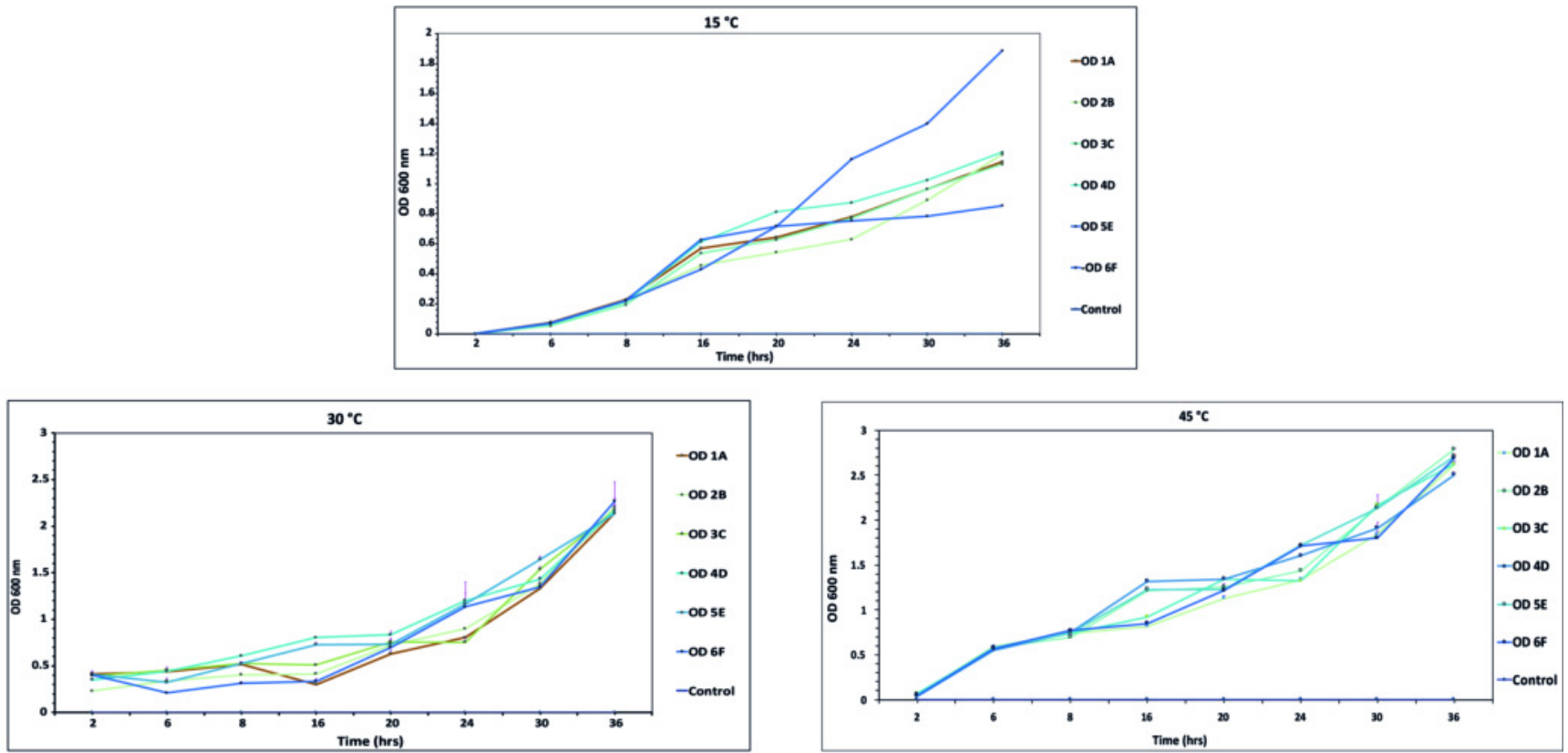
Table $\mathbf{1}$ (on next page)

Cellular characteristics of biodegrading pesticide isolates

NA 
1

2

3 Table 1. Cellular characteristics of biodegrading pesticide isolates.

4

\begin{tabular}{|l|l|l|l|l|l|l|}
\hline $\begin{array}{l}\text { Isolate } \\
\text { code }\end{array}$ & Media used & $\begin{array}{l}\text { Shape of } \\
\text { cells }\end{array}$ & $\begin{array}{l}\text { Cell size } \\
(\boldsymbol{\mu m})\end{array}$ & Motility & $\begin{array}{l}\text { Gram } \\
\text { staining }\end{array}$ & Endo-spores \\
\hline 1A & Nutrient Agar & Rods & 1.5 & Motile & negative & Negative \\
\hline 2B & - do- & Rods & 2.0 & Motile & - do- & -do- \\
\hline $3 \mathrm{C}$ & - do- & Rods & 2.5 & Motile & - do- & -do- \\
\hline 4D & - do- & Coccus/rod & 1.5 & Non motile & -do- & -do- \\
\hline $5 \mathrm{E}$ & - do- & Rods & $1.5-3.0$ & Motile & -do- & -do- \\
\hline $6 \mathrm{~F}$ & - do- & Rods & 2.2 & Mitile & -do- & -do- \\
\hline
\end{tabular}

5 


\section{Table 2 (on next page)}

Sequence identity (\%) of the partial 16S rRNA gene sequence of isolates obtained from environmental samples with related microbes

NA 
1 Table 1. Sequence identity (\%) of the partial 16S rRNA gene sequence of isolates obtained from 2 environmental samples with related microbes

\begin{tabular}{|c|c|c|c|c|c|}
\hline $\begin{array}{l}\text { Isolate with } \\
\text { codes }\end{array}$ & $\begin{array}{l}\text { Base } \\
\text { pairs }\end{array}$ & Top Hit with & \% Identity & $\begin{array}{c}\text { Gap } \\
\%\end{array}$ & $\begin{array}{c}\text { GenBank Accession } \\
\text { No. }\end{array}$ \\
\hline $1 \mathrm{~A}$ & 797 & $\begin{array}{c}\text { Pseudomonas } \\
\text { aeruginosa strain N7 } \\
(\mathrm{MH} 393215.1)\end{array}$ & 99.13 & 0 & HM215142.1 \\
\hline $2 \mathrm{~B}$ & 796 & $\begin{array}{c}\text { Pseudomonas } \\
\text { aeruginosa strain } \\
1816 \text { (MK078036.1) }\end{array}$ & 97.67 & 0 & HM215143.1 \\
\hline $3 C$ & 808 & $\begin{array}{l}\text { Pseudomonas sp. } \\
\text { strain 1AP-CY } \\
\text { (MT084588.1) }\end{array}$ & 99.02 & 0 & HM215144.1 \\
\hline 4D & 798 & $\begin{array}{c}\text { Pseudomonas } \\
\text { aeruginosa strain JU- } \\
\text { Ch1 (KF146882.1) }\end{array}$ & 98.40 & 0 & HM215145.1 \\
\hline $5 \mathrm{E}$ & 780 & $\begin{array}{c}\text { Acinetobacter } \\
\text { baumannii strain } \\
\text { SHRRWY.80 } \\
\text { (MT551041.1) }\end{array}$ & 97.99 & 0 & HM215146.1 \\
\hline $6 \mathrm{~F}$ & 307 & $\begin{array}{l}\text { Acidothiobacillus } \\
\text { ferroxidans } \\
\text { (AY956336.1) }\end{array}$ & 95.94 & 3 & HM215147.1 \\
\hline
\end{tabular}

3 